\title{
A mediação materna de Maria em Cristo na Encicliea Redemptoris Mater de João Paulo II segundo aprecią̧ão de Joseph Ratzinger'
}

\section{The maternal mediation of Mary in Christ in the Encyclical Redemptoris Mater of João Paulo II second assessment of Joseph Ratzinger}

\section{Lazaro Ilzo Daniel*}

Recebido em: 07/04/2020. Aceito em: 25/04/2020.

Resumo: Este artigo aborda a mediação materna de Maria associada à única mediação de Cristo, conforme a Redemptoris Mater (RMa), tendo como elemento fundante o comentário de Joseph Ratzinger. Busca-se o avanço na discussão teológica do tema a partir do confronto de ideias centrais do pensamento de João Paulo I/ sobre a mediação materna de Maria e do pensamento de Ratzinger sobre a RMa, bem como de seus demais estudos sobre a participação de Maria na obra salvadora de Jesus. O artigo, com base no método descritivo-dialético, busca responder o que é comum ao pensamento de ambos; o que é divergente no comentário de Ratzinger; e que dados novos podem ser aduzidos para o desenvolvimento teológico do tema da mediação de Maria.

Palavras-chave: Mediação materna. Redemptoris Mater. Maria. Jesus. Teologia.

Abstract: This paper deals with Mary's maternal mediation in association with the unique mediation of Christ, according to the Redemptoris Mater, based on Joseph Ratzinger's work. It seeks to advance the theological discussion of the

* Doutorado em Teologia (Facoltà di Teologia di Lugano, FTL, Suíça, 2010). Mestre em Teologia Dogmática (Facoltà di Teologia di Lugano, FTL, Suíça, 2003). Graduado em Teologia (Faculdade Entre Rios, FAERPI, 2015). Graduado em Filosofia (Faculdade Entre Rios, FAERPI, 2015). Graduado em Pedagogia (Faculdade de Ciências de Wenceslau Braz, FACIBRA, 2017). Graduado em História (Centro Universitário Claretiano, Batatais, 2017). Graduado em Ciências Sociais (Centro Universitário Claretiano, Batatais, 2019).

E-mail: pelazarodaniel@icloud.com.

1 O presente trabalho integra a produção do estágio pós-doutoral em Teologia realizado na PUC-Rio, com a supervisão do Prof. Antonio Luiz Catelan Ferreira. 
topic based on a comparison of John Paul II's central ideas regarding Mary's maternal mediation and Ratzinger's thoughts about the RMa and his additional studies on Mary's role in Jesus' saving work. The paper is based on a descriptive-dialectical method and deals with the question of what is common to both John Paul II and Ratzinger's ideas; what is unique about Ratzinger's commentary on the topic; and new data that can be adduced to the theological development of Mary's maternal mediation.

Keywords: Maternal mediation. Redemptoris Mater. Mary. Jesus. Theology.

\section{Introdução}

O objetivo deste artigo é avançar a discussão teológica do tema da mediação materna de Maria associada à única mediação de Cristo, segundo a Redemptoris Mater (RMa). Assume-se, para tanto, o comentário de Joseph Ratzinger como fundamento. O artigo busca confrontar as ideias centrais do pensamento de João Paulo II sobre a mediação materna de Maria com o pensamento de Ratzinger sobre a RMa e seus demais estudos sobre a participação de Maria na obra salvadora de Jesus. Tal confrontação dialética é produto da descrição do pensamento de cada autor sobre o tema, considerando a bibliografia crítica encontrada.

$\mathrm{O}$ artigo adota o método descritivo-dialético para responder às seguintes perguntas de pesquisa:

1. O que há de comum no pensamento de João Paulo II e Ratzinger?

2. O que há de descontinuidade no comentário de Ratzinger sobre o tema?

3. Que novos dados podemos recolher para o desenvolvimento teológico do tema da mediação de Maria, a Mãe de Jesus?

Sobre a organização do artigo: além desta introdução, a seção 2 aborda a Encíclica RMa e o tema da mediação materna. A seção 3 aprofunda o tema da mediação materna na RMa, e a 4 o faz segundo Ratzinger. A seção 5 expõe os elementos hauridos na análise comparativa. E, finalmente, a seção 6 conclui o artigo.

\section{A Encíclica Redemptoris Mater (1987) e o Tema da Mediação Materna}

A raiz profunda da Encíclica $R M a$ está no Concílio Vaticano II, especialmente no capítulo VIII da LG. Este é outro exemplo de uma leitura e 
de uma busca sistemática dos ensinamentos desse Concílio no magistério de João Paulo II que deixa transparecer a modalidade e a espiritualidade próprias do autor. Em seu capítulo Mariano, o Concílio não quer dar um progresso quantitativo, adicionando novas verdades dogmáticas e até mesmo apresentar uma completa, preferindo o aprofundamento da reflexão e da Mariologia à apresentação da doutrina sobre Maria. Desse modo, integrando-o na história da salvação e, assim, tentando seguir, sobretudo, direções bíblicas, Patrísticas e litúrgicas.

O Papa João Paulo II escreveu a Encíclica Redemptoris Mater por ocasião do Sínodo extraordinário, realizado para o $20^{\circ}$ aniversário do Concílio Vaticano II. Nesse contexto, mariano, o Papa estabelece a comemoração do aniversário dos dois milênios do nascimento de Cristo. Mas, para que possa se preparar, deve ser precedido por um ano de Jubileu, para enfatizar Maria como a brisa do advento, a mãe dele, segundo a carne e de acordo com o Evangelho. Ela é a estrela da manhã e, anunciando a aurora, precede o novo sol que é Cristo (RMa 3).

A Encíclica também recorda o décimo terceiro ano da Exortação Apostólica Marialis Cultus (1974). Embora o Papa a mencione apenas uma vez no número 2, segue os seus contornos grandes principais, ou seja, notas e orientações que devem conduzir ao culto da Virgem Maria, de acordo com a liturgia reformada e com a piedade popular e de acordo com o espírito do Concílio. A Encíclica Redemptoris Mater realça as características trinitárias, cristológicas e os traços de característica eclesial da Marialis Cultus, bem como suas diretrizes bíblicas, litúrgicas, ecumênicas e catequéticas.

\section{A Mediação Materna: Maria, Serva do senhor}

Seguindo a mesma estrutura da Lumen Gentium (LG 60), a Enciclica RMa busca evitar qualquer possibilidade de confusão que coloque a mediação de Maria na mesma ordem da mediação de Cristo: “[o] papa, sobretudo sob a perspectiva bíblica, para chegar a um entendimento também com os protestantes, apresenta a doutrina de mediação de Maria, a qual estes não aceitam, com base na existência de um único mediador, sustentado por São Paulo (1 Tm 2,5-6)". ${ }^{2}$

2 CALKINS, A. B. Mary, Mediatrix off All Graces, in the Papal Magisterium of Pope John Paul II. In: FEHLNER, P. D. M. (Ed.). Mary at the Foot of the Cross - VII: Coredemp- 
Assim, a mediação de Maria é por participação e está no plano das criaturas. Ela colabora com a única mediação de Cristo de forma extraordinária. A mediação é especificada por sua maternidade divina. João Paulo II apresenta sinteticamente essa peculiar e única maternal mediação que é adequada a Ela, que é a mãe de Cristo, parceira generosa na obra da redenção e, para nós, mãe na ordem da graça (LG 61):

Efetivamente, a mediação de Maria está intimamente ligada à sua maternidade e possui um carácter especificamente maternal, que a distingue da mediação das outras criaturas que, de diferentes modos e sempre subordinados, participam na única mediação de Cristo; também a mediação de Maria permanece subordinada (RMa 38).

Em nota, o Papa refere-se a São Bernardo, que fala de mediatrix ad Mediatorem: "Maria, como um límpido espelho, reenvia para o filho toda glória e honra que recebe". ${ }^{3}$ Portanto, ensina que o papel mediador de Maria está associado à única mediação de Cristo:

A mediação de Maria está intimamente ligada à sua maternidade divina, ela é mediadora como mulher, como a Mãe de Jesus, a ele associada na terra (oração, obediência, sofrimento), no céu (intercessão) e, portanto, é especial e extraordinária comparada à nossa mediação, e associa-nos a si para a salvação de todos [...] ela tem sido companheira generosa de Jesus na ordem da graça e serva do Senhor no plano da salvação e, portanto, torna-se nossa mãe na ordem da graça. ${ }^{4}$

Para entender o papel de Maria, é necessário contemplar os eventos da Anunciação e da Encarnação. Nestes, a entrega de Maria é participação, da única mediação entre Deus e o homem, do mediador Jesus Cristo, a Palavra Encarnada. É a aceitação da maternidade como pleno consentimento da Palavra de Deus, é o resultado de sua entrega total a Deus na virgindade com amor exclusivo, totalmente dedicada a Deus.

trix, Therefore Mediatrix of All Graces. New Bedford, MA: Academy of the Immaculate, 2008. p. 34-39.

3 RMa 38, nota 96: San Bernardo, In Dominica infra octavam. Assumptionis Sermo 2: S. Bernardi Opera, V, p. 263. San Bernardo. In Nativitate B. Mariae Sermo De aquaeductu, 12: S. Bernardi Opera V, p. 283.

4 BERTETTO, D. Il contenuto e le caratteristiche dell'Enciclica Redemptoris Mater. Palestra del Clero 6. Rovigo: Editora Alberto Brigo, 1987. p. 1382 (Tradução nossa). 
A característica essencial da maternidade virginal de Maria é o seu ser genuíno e pessoal: a "serva do senhor" (Lc 1,38), a bem-aventurada "que acreditou" (Lc 1,45). Enquanto, diante de seus olhos e em seu espírito, manifesta-se a missão do seu filho, ela colabora com a sua dimensão maternal. Assim, avançando na peregrinação da fé até o momento da Cruz, Maria se transforma, fundamentalmente, na primeira discípula de seu filho. Ela é a primeira chamada e a primeira a segui-lo. Então, ela não é só a mãe-cuidadora do Filho do Homem, mas também sua generosa companheira de modo singular (LG 61, RMa 39).

No momento da plena manifestação da Igreja ao mundo, no dia de Pentecoste, vê-se a continuidade da maternidade de Maria, presente no seio da Igreja nascente, enquanto implora com a sua intercessão a vinda do Espírito Santo (RMa 23-24, 40). Quando levada ao céu, terá lugar nela todos os efeitos da mediação do Redentor, Maria continua unida ao seu Filho até reinar com ele, sempre como aquela que Nele acreditava e que o servia. Agora, participa da glória de continuar a servir maternalmente, intercedendo pelos homens, até o coroamento de todos os eleitos.

O Papa conclui essa parte sobre a dimensão escatológica da mediação de mariana, com base em São Bernardo, que apresenta Maria "unida por um estreito e indissolúvel vínculo" a Cristo, a serva do senhor, "Medianeira de clemência", ou seja, imperatriz de clemência junto ao seu filho enquanto juiz universal. Maria é glorificada como rainha do universo e também como rainha-serva, pois continua a cooperar de modo subordinado ao seu filho, até a plenitude do tempo quando Ele reunirá em Cristo todas as coisas (EF 1,10$){ }^{5}$

\subsection{Conclusão da RMa}

O ano Mariano termina com a festa da Assunção corpórea de Maria ao céu. Na conclusão da Encíclica, João Paulo II foca de modo dramático o tempo presente, contextualizando-o no antigo hino Alma Redemptoris Mater. Assim, Maria, a mulher de fé, é também mãe pressurosa, que, em tensão escatológica, socorre os irmãos de seu Filho no decorrer da história humana, que adquire perfil de análise conclusiva, tendo em vista a proximidade do jubileu do ano 2000 .

5 RMa 41, nota 110: San Bernardo, In Dominica infra octavam. Assumptionis Sermo, 1-2: S. Bernardi Opera V, p. 262s. 


\section{O Tema da Mediação na RMa segundo Ratzinger}

No terceiro capítulo do livro "Maria Primeira Igreja", ${ }^{6}$ intitulado "O Sinal da Mulher. Ensaio de introdução à Encíclica Redemptoris Mater", está a fonte basilar do nosso estudo. Segundo Ratzinger, a Encíclica RMa não obteve grande aceitação no mundo católico alemão dada a preocupação exagerada com a questão ecumênica e com o suposto crescimento demasiadamente emocional da piedade mariana. Contudo, o feminismo trouxe elementos novos à questão mariológica. Se, por um lado, a imagem de Maria é a representação da dependência da mulher e a glorificação da sua opressão (enquanto serva obediente exaltada pela sua submissão), por outro lado, Maria pode vir a oferecer, na sua figura, o princípio para uma nova interpretação da Sagrada Escritura.

Para evitar interpretações tendenciosas, deve-se escutar de modo afinado o que a Bíblia diz sobre Maria. Para tanto, "poderia ser esta hora de escutar com mais atenção do que de costume uma encíclica sobre Maria cuja preocupação primeira é fazer falar os textos bíblicos". ${ }^{7}$

\subsection{Aspectos Metodológicos}

Ratzinger destaca aspectos metodológicos usados pelo Papa João Paulo II na construção do texto da Encíclica RMa.

\subsubsection{Leitura global da Bíblia}

A RMa apresenta a citação de longas passagens como uma meditação bíblica. Posteriormente, produz uma interpretação de cunho teológico, seguindo a regra fundamental dada pela Constituição Dei Verbum sobre a Revelação da Sagrada Escritura, que, no número 12, expressa: "[...] a Sagrada Escritura deve ser lida e interpretada naquele mesmo espírito com que foi escrita". ${ }^{8}$ Ela possui, então, uma unidade interna e histórica que suporta e une o humano e o divino. Sem esse método histórico, seria impossível destacar e delimitar todos os seus aspectos, isto é, a Escritura interpreta a si própria.

6 RATZINGER, J. Maria Primeira Igreja. Coimbra: Gráfica de Coimbra, 2004. p. 33-58

7 RATZINGER, J., 2004, p. 33.

8 KLOPPENBURG, F. B. Compêndio do Vaticano II. Constituições, decretos e declarações. 29. ed. Petrópolis: Vozes, 2000. p. 130. 
A verdade da Escritura em sua globalidade, portanto, é a sua própria atualidade, enquanto falante a um sujeito atual, os homens, pois apresenta a mensagem sobre Deus a eles. Trata-se, assim, da posição do Papa ao falar de modo meditativo com a Bíblia na Encíclica RMa.

\subsubsection{A Linha feminina na Bíblia}

Para Ratzinger, a Encíclica RMa conduz a redescobrir a linha feminina da Bíblia, que, com o seu conteúdo soteriológico, não somente não reduz à insignificância a cristologia, mas, pelo contrário, a correlação de ambos, de modo justo e equilibrado, revelando verdade sobre Deus e a humanidade.

Na modernidade desenvolveu-se, a partir da mensagem biblica, e por outros motivos, uma exclusão do feminismo menos radical mas não menos eficaz: uma hipertrofia do solus Christus obrigou a rejeitar como traição à grandeza da graça de qualquer colaboração da criatura, qualquer significado autônomo. ${ }^{9}$

Assim, a leitura mariana da Bíblia proposta por João Paulo II, a exegese da totalidade do dado bíblico em relação a Jesus e Maria seja no Antigo Testamento, que vai de Adão até os patriarcas e de Eva e das santas mulheres (Débora, Ester) até Sophia (Sabedoria), seja no Novo Testamento, na relação de Cristo e Maria e Maria e a Igreja num entrelaçamento entre a cristologia e a mariologia, e esta com a eclesiologia - poderá responder aos desafios antropológicos atuais. Estes que, por vários radicalismos, "deslocam a luta de classes para a raiz do que é o ser humano (na existência um para o outro do homem e da mulher) são 'heresia' no sentido literal do termo: é uma escolha que rejeita a globalidade". ${ }^{10}$

\subsubsection{Uma mariologia histórica e dinâmica}

Segundo Ratzinger, a especificidade do pensamento mariológico da RMa reside num visível deslocamento de ordem linguística. Inversamente à mariologia anterior, sobretudo do século XIX e início XXI,

9 RATZINGER, J., 2004, p. 40.

10 RATZINGER, J., 2004, p. 41. 
que cercava apresentar Maria desde os seus privilégios e títulos, aqui encontramos Maria presente e ativa na história humana. Portanto, a RMa, apresenta o ser de Maria associado à sua missão histórica, como veremos desenvolvido sobretudo no tema da mediação materna.

\subsection{Pontos Focais do Pensamento de Ratzinger sobre a RMa: Maria, a mulher de fé-participativa}

A fé é atitude central de Maria - bem-aventurada és tu que acreditaste $(\mathrm{Lc} 1,45)$. As palavras pronunciadas pela sua prima Isabel são consideradas por Ratzinger as "palavras-chaves" de toda a mariologia da RMa, sem as quais não poderia haver uma reta compreensão da Encíclica. A fé de Maria é comparada à de muitas testemunhas da fé, como Abraão, pois, se com ele deu-se o início da primeira Aliança com Deus, a fé de Maria é início da Nova Aliança, segundo relato da Anunciação do Anjo Gabriel (Lc 1,26-38). À semelhança de Abraão, a fé de Maria é "confiança em Deus e obediência a Deus, embora por um caminho obscuro" (RMa, 14). ${ }^{11}$

Para Ratzinger, o ponto de partida dessa comparação está na RMa 13. Tendo como base Heb 10,5-7, que interpreta S1 40,6-8: "Não quiseste sacrifícios nem oferenda, mas preparaste-me um corpo... sim, eu venho... para fazer, ó Deus, a tua vontade", o sim de Maria é identificado com o sim de seu Filho. Ratzinger cita Santo Agostinho: "o prius mente quam ventre", ou seja, antes de conceber no ventre, Maria concebeu no coração.

Maria em pé junto à cruz de Jesus - momento auge da sua atitude meditativa da fé crucificante - quenose e abandono na obscuridade total, pois, enquanto, fiel conservadora das promessas de Deus, que prometera que seu filho Jesus viria a receber o trono de Davi que jamais teria fim ( $\mathrm{Lc}$ 1,32-35). No evento da cruz, tal promessa parecia vir a ser desmentida. Em tal obscuridade, Maria participa de modo pleno do aniquilamento de Jesus e é precisamente aí que a sua fé se torna comparável à de Abraão, isto é, comunhão na cruz: lugar das bem-aventuranças que vem de Deus. ${ }^{12}$

\subsubsection{O sinal da mulher}

Ratzinger nota que, se o tema de Maria como a crente na RMa apresenta uma catequese sobre a fé, aqui teremos uma segunda linha de pensamento. Esta é uma catequese que aponta Maria como guia da

11 RATZINGER, J., 2004, p. 46.

12 RATZINGER, J., 2004, p. 48. 
história, sinal dos tempos, e, com base no capítulo 12 de Apocalipse, relacionando-o com Gn 3,15, ${ }^{13}$ o protoevangelho, revela-nos o sinal da mulher, atribuído à Mãe de Jesus. Segundo os Padres, a maldição contra a serpente após a pecado original, a primeira promessa de Redenção, "não houve na história um único instante sem Evangelho. No momento da queda começa também a promessa". ${ }^{14}$

Tal processo reaparece em Apocalipse 12, na mesma síntese histórica de tensão dramática: “[o] drama da história entrou na sua hora decisiva. Mas esta decisão agora já antecipada no que se passou em Nazaré: aí o anjo havia dito a Maria 'Ave, ó cheia de graça', e Maria surge agora como mulher definitivamente abençoada". ${ }^{15}$

Nessa perspectiva, para Ratzinger, João Paulo II, naquele ano mariano, "quer, no nosso momento histórico, apresentar o "sinal da mulher" como o "sinal dos tempos" essencial". ${ }^{16}$ Portanto, Maria, a "cheia de graça", concebe Cristo com o seu "sim" no momento da Anunciação que nos salvará do poder do mal, e ela é, para a humanidade sofredora, sinal indicador de esperança e de benção.

\subsubsection{A mediação de Maria}

O terceiro ponto de vista de Ratzinger sobre a RMa é o da mediação de Maria, tratado de forma minuciosa e aprofundada pelo Papa João Paulo II, que, no Concílio Vaticano II, já havia se referido ao tema, citando o título de "mediadora" ${ }^{17}$ e da "função da mediação de Maria". ${ }^{18} \mathrm{~A}$ RMa, por sua vez, nada acrescenta de novo no que se refere ao conteúdo, mas o aprofunda e fornece uma melhor compreensão, seja para a mariologia seja para a vivência da espiritualidade mariana.

\subsubsection{Conceitos}

O caráter da única mediação de Cristo é sublinhado pela RMa, que enfatiza seu aspecto exclusivo e, somente depois, apresentando outras

\footnotetext{
13 "Porei ódio entre ti e a mulher, entre a tua descendência e a dela. Esta te ferirá a cabeça, e tu ferirás o calcanhar".

14 RATZINGER, J., 2004, p. 49.

15 RATZINGER, J., 2004, p. 49.

16 RATZINGER, J., 2004, p. 50.

17 Lumen Gentium 62.

18 Lumen Gentium 60 e 62.
} 
formas de mediação participada, isto é, cada ser humano em comunhão de proximidade com Deus, torna-se de fato mediador para o outro. ${ }^{19}$

Possibilidades, limites e terminologia da mediação: a mediação de Maria é participação "no ministério de mediação de Cristo, e é comparada com este um serviço subordinado (RMa 39)", ${ }^{20}$ tem seu fundamento na mediação de Cristo, dele depende e dele tira toda a sua eficácia (RMa 22; LG 60) e realiza-se sob a forma de intercessão (RMa 21).

\subsubsection{Caráter específico e extraordinário da mediação de Maria}

Maria, enquanto criatura, não se distingue das demais quanto à mediação humana; porém, há algo de extraordinário e especial na mediação de Maria para além do possível, na "comunhão dos santos" para os demais cristãos: "[a] tese fundamental do Papa é a seguinte: a especificidade na mediação de Maria é o facto de ser mediação maternal, em ordem a um sempre novo nascimento de Cristo no mundo". ${ }^{21}$

A intervenção de Maria nas bodas de Caná mostra a presença feminina no acontecimento da salvação, no qual, além de uma visão institucional da Igreja, para além de uma representação desta na figura de Maria, sublinha-se o entrelaçamento de mais uma passagem escriturística da RMa:

Sinto por vós de novo as dores do parto, até que Cristo seja formado em vós $(G l 4,19)$. A vida não acontece através do puro fazer, mas sim através do nascimento e exige, portanto, as dores do parto. A "consciência maternal da Igreja primitiva" que o Papa aponta, diz-nos respeito a nós precisamente, hoje também (RMa 43).22

O autor, de modo pedagógico e incisivo, pergunta: "por que temos de ver esta dimensão feminina e maternal da Igreja fixada para sempre em Maria?".

Duas citações escriturísticas coligadas responderão a essa indagação. A mulher desconhecida, entusiasmada pela pregação de Jesus

\footnotetext{
19 RATZINGER, J., 2004, p. 51.

20 RATZINGER, J., 2004, p. 52.

21 RATZINGER, J., 2004, p. 53.

22 RATZINGER, J., 2004, p. 53.
} 
e o louvor do corpo que deu a vida a Ele (Lc 11,28), e o texto de Lc 8,20 s, no qual Jesus diz expressamente: "[m]inha mãe e meus irmãos são aqueles que ouvem a palavra de Deus e a põem em prática". Além do nascimento físico de Cristo, que aconteceu uma vez, há uma outra dimensão da maternidade que continua a existir no caso de Maria - a maternidade que fez nascer Cristo e continua a fazê-lo nascer é fruto da escuta e da conservação no coração da Palavra. Isso é evidente na obra lucana:

No Pentecoste, no momento do nascimento da Igreja graças ao Espírito Santo, isto torna-se concreto: Maria está no centro da comunidade orante que, graças à descida do Espírito se torna Igreja. A correspondência entre a encarnação e o nascimento da Igreja no Pentecostes é iniludivel. ${ }^{23}$

A mediação materna de Maria é plenamente desenvolvida na RMa no texto Evangelho de João (Jo 19-26-27) - nas palavras de Jesus na cruz: "Eis a tua mãe" e "Mulher, eis aí o teu filho" - considerado por João Paulo II como o testamento de Cristo na cruz, no qual Jesus doa a sua mãe aos seres humanos como mãe. Eis uma nova maternidade que surge do amor de Maria enquanto fruto amadurecido dessa mulher aos pés da cruz (RMa 23 e 45).

Ratzinger sublinha, ainda, que a RMa apresenta uma sutil interpretação de Jo 19,27: "E, dessa hora em diante, o discípulo a levou para a sua casa" - acentuando que a tradução literal seria: "Ele tomou-a no que lhe é próprio":

Para o Santo Padre isto significa uma relação profundamente pessoal entre o discípulo - todo o discípulo - e Maria, uma apreensão de Maria no mais íntimo da própria vida espiritual e eclesial, uma entrega e uma entrada na sua existência feminina e maternal, uma total consignação um ao outro, que é sempre a formação de Cristo no ser humano. Mas, assim, a tarefa mariana ilumina a figura da mulher em geral, a dimensão do feminino e a tarefa especial da mulher na Igreja (RMa 46). ${ }^{24}$

Portanto, entrelaçados, todos os textos escriturísticos da RMa formam um único tecido, pois nem o texto joanino descrito nem o evento das bodas de Caná nomeiam Maria pelo nome, mas a chamam de "Mulher".

23 RATZINGER, J., 2004, p. 54.

24 RATZINGER, J., 2004, p. 55. 
No entanto, coligados e entrelaçados com os textos de Gn 3 e Ap 12, já analisados na Encíclica, demonstram, numa interpretação válida no seu conteúdo simbólico, que essa Mulher é Maria.

Em conclusão, do tema da mediação, a RMa 47 cita uma frase do Papa Paulo VI que se refere a Maria como Mãe da Igreja, a nova Eva, que "continua no céu a sua tarefa maternal a favor dos membros de Cristo, na medida que participa no nascimento e na formação da vida divina nas almas dos redimidos". 25

\section{Análise Sistemática Comparativa}

Do comentário de Ratzinger sobre a RMa, extraímos ideias fundamentais quanto à compreensão desta e, sobretudo, do tema da mediação materna de Maria.

\subsection{Leitura global da sagrada Escritura}

A verdade da Escritura, interpretada em sua globalidade, e não a partir de textos isolados, mas em relação de unidade e continuidade entre a história do povo de Deus, conduz a própria atualização, pois apresenta a mensagem sobre Deus a eles em sua realidade histórica. Ratzinger já utilizava o método no livro "A Filha de Sião", que traz três conferências feitas em 1975 sobre a piedade mariana. Maria, à luz dos textos do Antigo e do Novo Testamento, "incorpora a continuidade no silêncio e na fé, que se consuma nos pobres de Israel, naqueles a quem são dirigidas as bem-aventuranças: felizes são os pobres 'em espírito"”. ${ }^{26}$

\subsubsection{A linha feminina na Sagrada Escritura}

Há vários radicalismos que dilaceram o nosso tempo, como a questão da mulher na Igreja e, sobretudo, a questão do papel único da mulher enquanto mediadora e colaboradora insubstituível, por ordem do gênero e da graça, no mundo e na Igreja. Capta-se, assim, a partir de Maria, na sua realidade de mulher-mãe-esposa, o sentido teológico da realidade de Maria como expressão da realidade eclesial-feminina da Igreja.

25 RATZINGER, J., 2004, p. 56.

26 RATZINGER, J., 2004, p. 57. 


\subsubsection{Mariologia histórica e dinâmica}

$\mathrm{Na} \mathrm{RMa}$, Maria está associada essencialmente à sua missão histórica, apresentada desde a interpretação bíblica da história salvífica do Antigo e do Novo Testamento em relação recíproca, como vimos - e que, sobretudo, será evidenciado no tema da sua mediação materna. Ratzinger, anos antes, havia percebido a profundidade do método da unidade de leitura global da Bíblia, tão útil para a Mariologia. ${ }^{27}$

\subsubsection{Bimilenarismo}

Mais do que celebrar de forma mágica e até o jubileu do ano mariano, Ratzinger insiste no sentido de "rememoração" do mistério de Cristo participado por Maria segundo a leitura unitária e global das Escrituras, que darão sentido ao ano mariano de 1987-1988.

\subsection{Doutrina Mariológica de Ratzinger a partir da RMa: Maria, a mulher de fé-soferente}

A fé é a atitude central de Maria, enquanto ela, a Bem-aventurada que acreditou (Lc 1,45), atualiza tal fé no momento de Anunciação, e o seu "sim" de Maria (Lc 1,26-38) transformam-se em um ato de fé de caráter crucificante (Jo 19, 26-27), no momento da entrega amorosa de seu filho, pois ela colabora com o Filho no projeto de Deus (Hb 10,5-7).

\subsubsection{Maria, a crente que se apresenta como guia histórico}

Maria, na sua atitude de fé operativa, é como "sinal dos tempos". Com base no capítulo 12 de Apocalipse, relacionado com Gn 3,15, o chamado protoevangelho, Maria é a "cheia de graça", que, ao conceber Cristo com o seu "sim" no momento da Anunciação, que o salvará do poder do mal, torna-se, para a humanidade sofredora, sinal indicador de esperança e de bênção.

\subsection{Mediação Materna de Maria}

Da interpretação de Ratzinger ao tema da mediação na terceira parte da RMa, podemos extrair os seguintes elementos de continuidade com o pensamento do Papa João Paulo II:

27 RATZINGER, J. A Filha de Sião. A devoção Mariana na Igreja: São Paulo: Paulus, 2014. p. 9. 
1. O caráter da única mediação de Cristo é sublinhado pela RMa, enfatizando seu aspecto exclusivo e, somente depois, apresentando outras formas de mediação participada.

2. A mediação de Maria é participação "no ministério de mediação de Cristo, e é comparada com este um serviço subordinado (RMa 39)", ${ }^{28}$ tem seu fundamento na mediação de Cristo, dele depende e dele tira toda a sua eficácia (RMa 22; LG 60) e realiza-se sob a forma de intercessão (RMa 21).

3. Se Maria, enquanto criatura, não se distingue das demais criaturas quanto à mediação humana, há algo de extraordinário e especial na mediação de Maria para além do possível, na "comunhão dos santos" para os demais cristãos.

4. O entrelaçamento de vários textos que, colocados em sinopse, fornecem elementos conceituais esplêndidos de profundidade e clareza: a mediação materna de Maria, a intervenção de Maria nas bodas de Caná junto à Cruz e em Pentecostes.

\subsubsection{Elementos de aprofundamento por parte de Ratzinger}

Como apresentado, Ratzinger pergunta: "por que temos que ver esta dimensão feminina e maternal da Igreja fixada para sempre em Maria?". ${ }^{29}$ A resposta comporta a conjunção de três acontecimentos:

1. A intervenção de Maria nas bodas de Caná traz a presença feminina no acontecimento da salvação, no qual, além de uma visão meramente institucional da Igreja, há uma representação da Igreja na figura de Maria.

2. A nova maternidade que surge do amor de Maria enquanto fruto amadurecido dessa mulher aos pés da cruz.

3. No Pentecoste, no momento do nascimento da Igreja graças ao Espírito Santo, a maternidade espiritual de Maria se torna concreta, pois ele está no centro da comunidade orante durante o nascimento da Igreja e da sua missão ad gentes.

Disso, concluímos que a mediação materna de Maria é exercida em favor de toda a humanidade. Michele Giulio Masciarelli é concorde ao

28 RATZINGER, J., 2004, p. 52.

29 RATZINGER, J., 2004, p. 53. 
afirmar que, ${ }^{30} \mathrm{em}$ seu discurso, Ratzinger "livra o tema da mediação de esquematismos consolidados anteriormente para dar-lhe uma interpretação ao máximo larga e difusa" e pressupõe que a mediação é ajuda para que alguém alcance a salvação. Tal ajuda é estrutural no cristianismo, no qual todos são chamados a ajudar. Assim, Maria, remida por Deus, é escolhida por Ele para ser mãe do salvador e ajudá-lo na obra de salvação de toda a humanidade:

Essa reciprocidade de mediação não deve, de forma alguma, ser entendida como uma forma de autorredenção e de autossalvação. Dito em termos marianos, a Virgem não é autorredimida (é o sentido da concepção imaculada), nem é mãe do Salvador (é o sentido da Anunciação); não entrou na missão da Igreja com uma decisão autônoma (é o significado de Pentecostes); nem é, ao final, autoglorificada (é o significado da suposição). ${ }^{31}$

Na sua mariologia, Ratzinger realiza um aprofundamento teológico, buscando equilíbrio entre o cristocentrismo, próprio do movimento litúrgico, e o devocionalismo mariano, presente na sensibilidade popular e, consequentemente, com a cristologia. Por isso, aprofunda-se no dogma da maternidade de Maria, pela pesquisa bíblica sobre a sua figura em suas raízes veterotestamentárias como Filha de Sião. Sem esquecer de explicar os dogmas da Imaculada Conceição e da Assunção, a partir da liturgia, dos textos bíblicos, e vincular a figura de Maria à Igreja. Assim, a mãe do Verbo Encarnado será imagem da primeira Igreja e a mãe dos fiéis, pois toda sua eficácia mediadora provém do seu "Fiat", pronunciado na Anunciação (Lc 1,26-38) e na colaboração com a missão redentora do seu amado Filho, como se vê na cena das bodas de Caná (Jo 2,1-12).

\section{Conclusão}

Retomam-se aqui as questões propostas na introdução. Quanto à primeira, observa-se que Ratzinger, seguindo o Papa João Paulo II, compreende a mediação de Maria, desde a análise global da Bíblia, como participação à única mediação de Cristo e a ela subordinada como as demais criaturas. Porém, com caráter específico de missão de serviço enquanto mãe de Cristo e da humanidade.

Sobre a segunda, nota-se que Ratzinger traz, de modo mais aprofundado, o caráter específico da mediação materna de Maria, tipificando-a como dimensão feminina e maternal da Igreja fixada para sempre em

30 MASCIARELLI, M. G. I/ segno della donna. Milano: San Paolo, 2007. p. 101-102.

31 MASCIARELLI, M. G., 2007, p. 102 (Tradução nossa). 
Maria, desde a análise da sua intervenção nas bodas de Caná, à sua presença junto à cruz do seu filho Jesus e no evento de Pentecostes, como ajuda em favor da humanidade. Assim, concluímos que Ratzinger permite recolher para o aprofundamento da Teologia da espiritualidade mariana que tenha como ponto de partida a realidade da fé de Maria e sua experiência existencial e o são ecumenismo. Partindo da mesma análise escriturística, possibilita um maior diálogo com os irmãos protestantes.

Finalmente, quanto à terceira questão, o tema da mediação de forma orgânica no interior da leitura global da Bíblia fornece elementos para o estabelecimento de um diálogo sobre a questão da maternidade de Maria enquanto realidade essencial para a salvação da humanidade e coadjutora com Deus para o nascimento de Jesus. E, da descoberta nos dados escriturísticos da vida de Maria desde a Anunciação até Pentecostes, o que é próprio da alma feminina em relação à sociedade possibilitará um maior diálogo entre a Teologia e a Antropologia em relação ao estudo da questão feminista.

\section{Referências}

BERTETTO, D. Il contenuto e le caratteristiche dell'Enciclica Redemptoris Mater. Palestra del Clero 6. Rovigo: EditoraAlberto Brigo, 1987. p. 1374-1381.

CALKINS, A. B. Mary, Mediatrix off All Graces, in the Papal Magisterium of Pope John Paul II. In: FEHLNER, P. D. M. (Ed.). Mary at the Foot of the Cross - VII: Coredemptrix, Therefore Mediatrix of All Graces. New Bedford, MA: Academy of the Immaculate, 2008. p. 34-39.

CARTA ENCÍCLICA REDEMPTORIS MATER (RM) DO SUMO PONTÍFICE JOÃO PAULO II. Carta Encíclica RM sobre a Bem-Aventurada Virgem Maria na vida da Igreja que está a caminho. Disponível em: $<\mathrm{ht}-$ tps://w2.vatican.va/content/john-paul-ii/pt/encyclicals/documents/hf jp-ii_enc_25031987_redemptoris-mater.html >. Acesso em: 05 set. 2018.

GIOVANNI PAOLO II.Lettera apostolica Spiritus Domini.AAS79,p. 1369, 1987. KLOPPENBURG, F. B. Compêndio do Vaticano II. Constituições, decretos e declarações. 29. ed. Petrópolis: Vozes, 2000.

MASCIARELLI, M. G. Il segno della donna. Milano: San Paolo, 2007.

PAOLO VI. Esortazione apostolica di su santità. Signum Magnum: $A A S$ 59, p. 467-468, 1967.

RATZINGER, J; BALTHASAR, H. V. Maria Primeira Igreja. Coimbra: Gráfica de Coimbra, 2004.

Paulus, 2014.

. A Filha de Sião. A devoção Mariana na Igreja: São Paulo: 